\title{
One Case of Refractory Condyloma Acuminatum in Children with Persistent HPV51 Infection Treated by Chinese Medicine Paiteling
}

\author{
Yang Meng, ${ }^{1,2 *}$, Huang Yaohui ${ }^{1}$, Zhu Qinghuan ${ }^{2}$, Lin Xiujuan ${ }^{1}$, Pan Yanbin ${ }^{1}$ and Li Jianmin ${ }^{1}$ \\ ${ }^{1}$ Department of Dermatology, the third affiliated hospital of Guangxi Medical University, China
}

${ }^{2}$ Department of Dermatology, the second affiliated hospital of Kunming Medical University, China

*Corresponding author: Yang Meng, Department of Dermatology, the third affiliated hospital of Guangxi Medical University, 13 Dancun Road, Nanning 530031, Guangxi, the second affiliated hospital of Kunming Medical University, Kunming, 650101, Yunnan, China

ARTICLE INFO

Received: 幽 March 04, 2020

Published: 幽 April 01, 2020

Citation: Yang M, Huang Y, Zhu Q, Lin X, Pan Y, et al., One Case of Refractory Condyloma Acuminatum in Children with Persistent HPV51 Infection Treated by Chinese Medicine Paiteling. Biomed J Sci \& Tech Res 26(5)-2020. BJSTR. MS.ID.004412.

Keywords: Condyloma Acuminata; Children; Paiteling; HPV51; Refractory

\begin{abstract}
A 3-year-old female presented with neoplasms on the perianal for1 month. Physical examination:Multiple needle tips appearing around the anus to millet size. A few vegetations are seen at the vaginal opening. Human papilloma virus (HPV) typing: HPV51 positive. HIV, TPPA, and RPR tests were negative. Histopathology of skin lesions: hyperkeratosis of the epidermis with incomplete keratosis, hyperplasia and hypertrophy of the spinous layer, papilloma-like hyperplasia, vacuolated cells seen above the spinal layer; Diagnosis: Condyloma acuminatum. Treatment: 4 times of photodynamic therapy was ineffective, HPV-51 continued to be positive, and then switched to the Chinese medicine Paiteling three-stage therapy. No new warts were found after follow-up for 1 year, and the HPV-51 turned negative.
\end{abstract}

Abbreviations: ALA-PDT: 5-Aminolevulinic Acid Photodynamic Therapy; CA: Condyloma Acuminate; HPV: Human Papilloma Virus

\section{Introduction}

Condyloma acuminate (CA), or anogenital verrucae, is a common sexually transmitted disease associated with human papilloma virus infection. It is principally transmitted through sexual intercourse and frequently occur in adolescents or adults. In the last decades, cases of CA in children gradually have increased that may be related to sexual abuse, vertical transmission and close contact with infected individuals. Guidelines for the treatment of CA in adults are available in the United States, but little has been published about the treatment in children [1]. At present the treatment options include destructive therapies such as cryotherapy and trichloroacetic acid, surgical excision, and topical modalities such as podophyllin, imiquimod, and sinecatechins [2]. But we know little about the safety and efficacy of these therapies in preadolescent children, there are not a consensus treatment guidelines of CA in children. The clinical treatment be directed based on the specific symptoms included the size, location and number of lesions. Paiteling is a pure traditional Chinese medicine preparation that has been used for the treatment of HPV infections in recent year [3]. Here, we report a case of refractory condyloma acuminata in a child treated with paiteling successfully.

\section{Case Report}

A 3-year-old female was admitted to our department with hyperplasia on the perianal for 1 month on June 12, 2018. A month ago, the mother of the child found several papules of needletip size around the anus when bathing her, without any special discomfort such as pruritus and pain. She did not pay attention to them. Later papules gradually increased and enlarged. She applied ointment such as "Dacron Cream" on her own, but there on any regression. The child's skin lesions kept increasing, so she came for diagnosis and treatment. There is nothing special about past and personal history. There was no similar lesions on her familly members. The child often plays in public swimming pools recently. Systematic physical examination showed no abnormality. 
Dermatological conditions found multiple needle-tip to millet size light pink hyperplasia around the anus and which were soft quality and partial fusion. A few vegetations were seen around the vaginal opening (Figures $1 \& 2$ ). Laboratory examination revealed the acetic acid white test was positive. Human papillomavirus test showed that HPV51 was positive and HPV11, HPV16, HPV18, etc were all negative. No abnormality was found in blood, urine, stool, HIV, TPPA and RPR examination (Figures 3-7). The histopathology of the skin lesions showed hyperkeratosis of epidermis with parakeratosis, acanthosis, papillomatosis and vacuolated cells in the upper part of stratum spinosum (Figures 8-9). The histopathological diagnosis was condyloma acuminata.

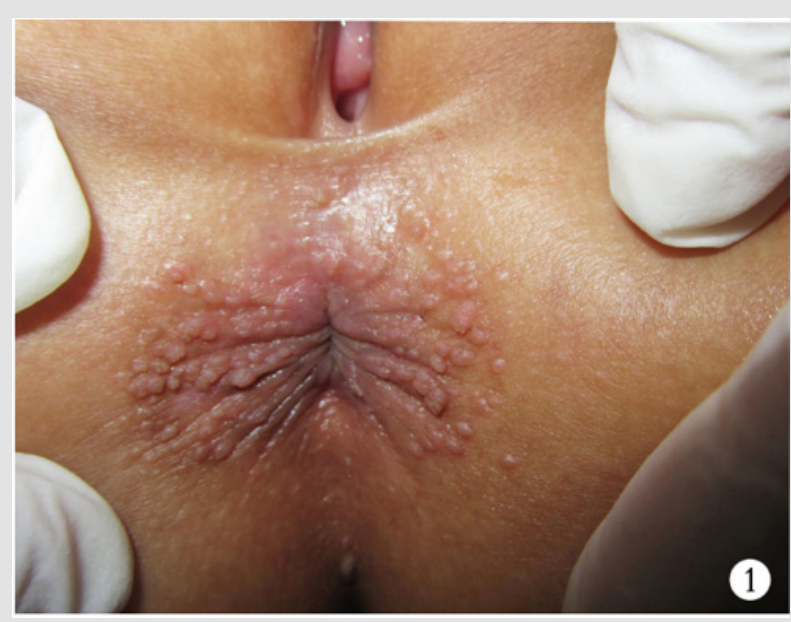

Figure 1: Skin lesions at the first consultation.

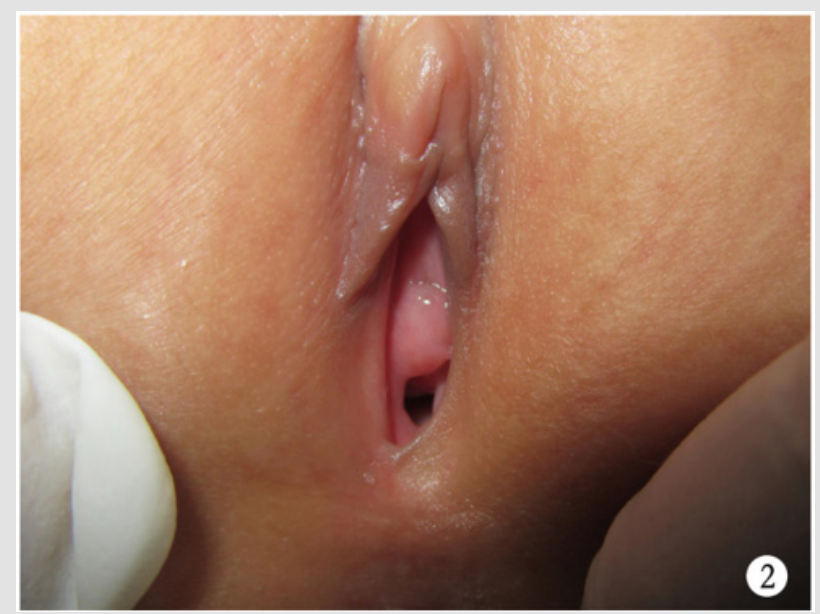

Figure 2: Skin lesions at the first consultation.

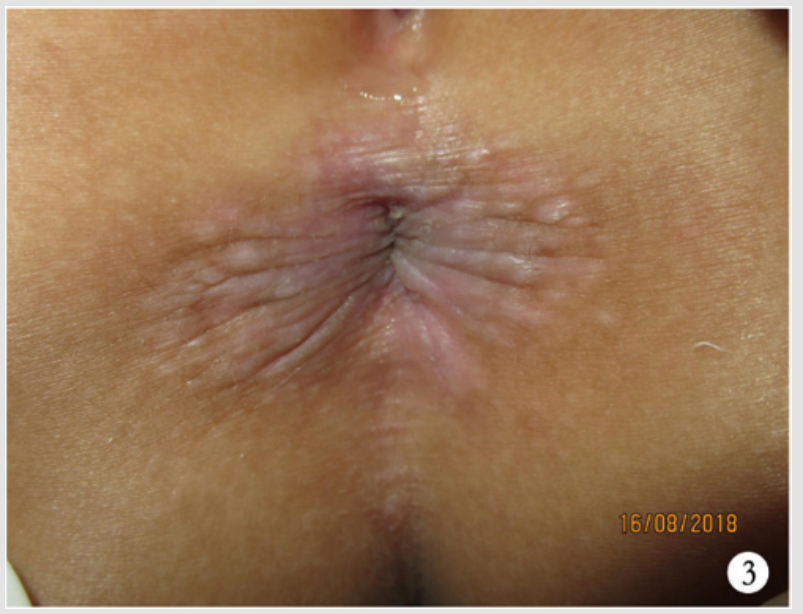

Figure 3: After the first stage of wart. 


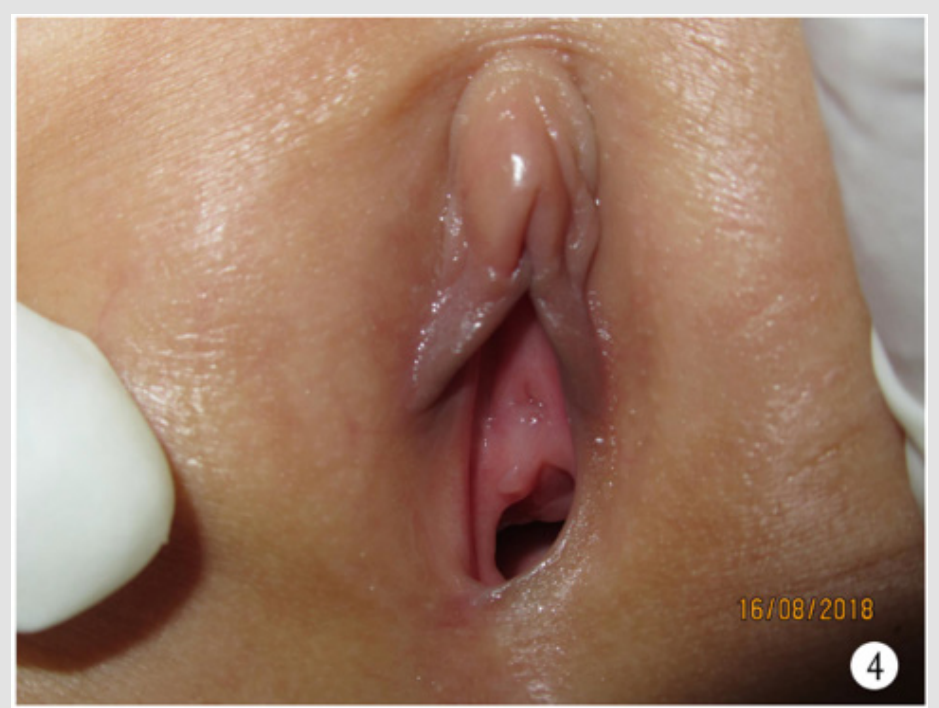

Figure 4: After the first stage of wart.

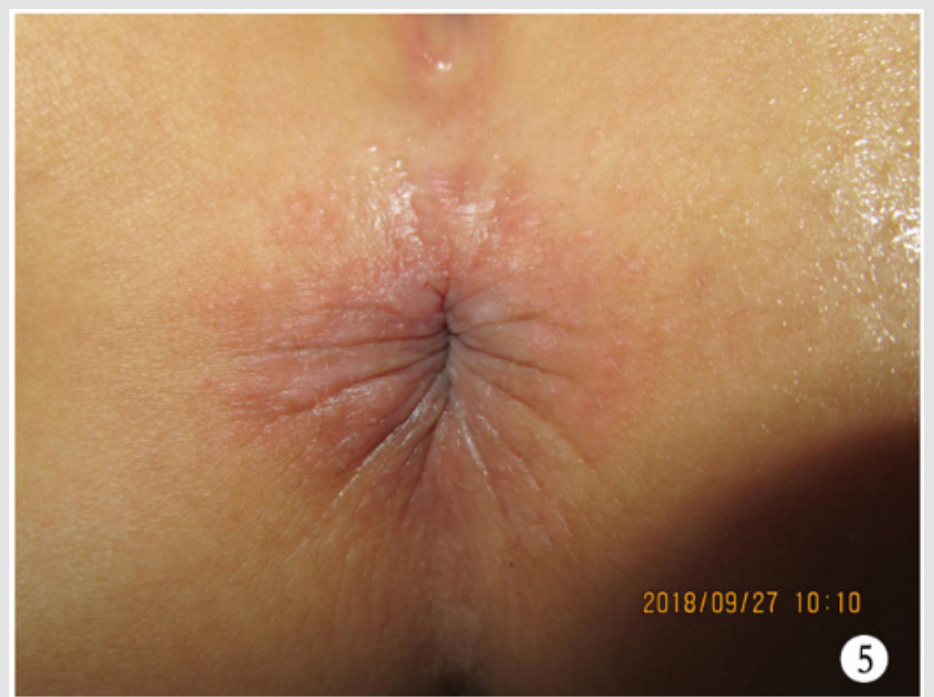

Figure 5: Phase III prevention of recurrence.

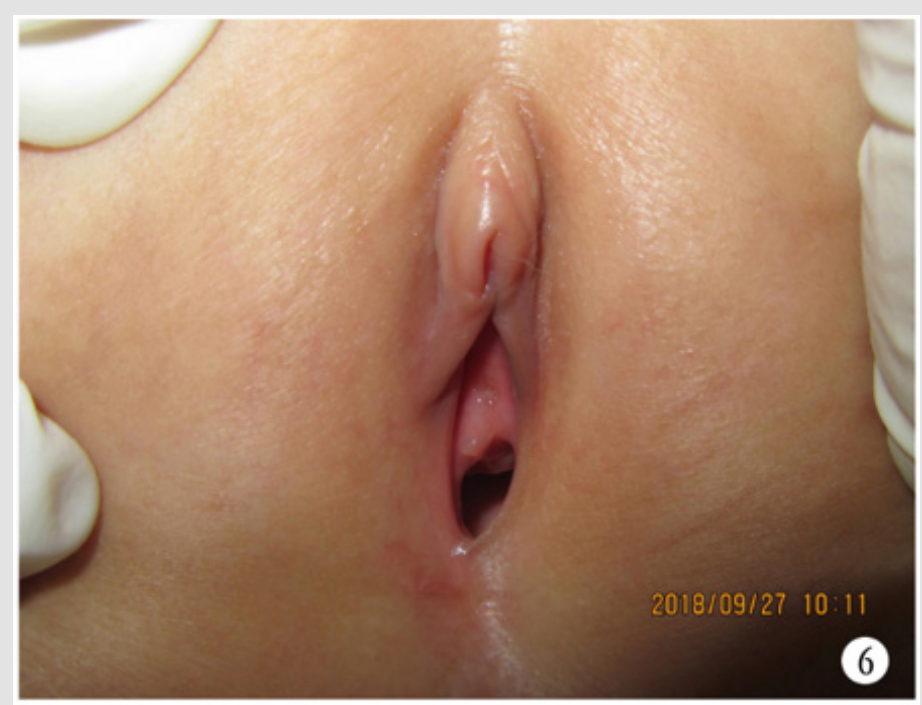

Figure 6: Phase III prevention of recurrence. 


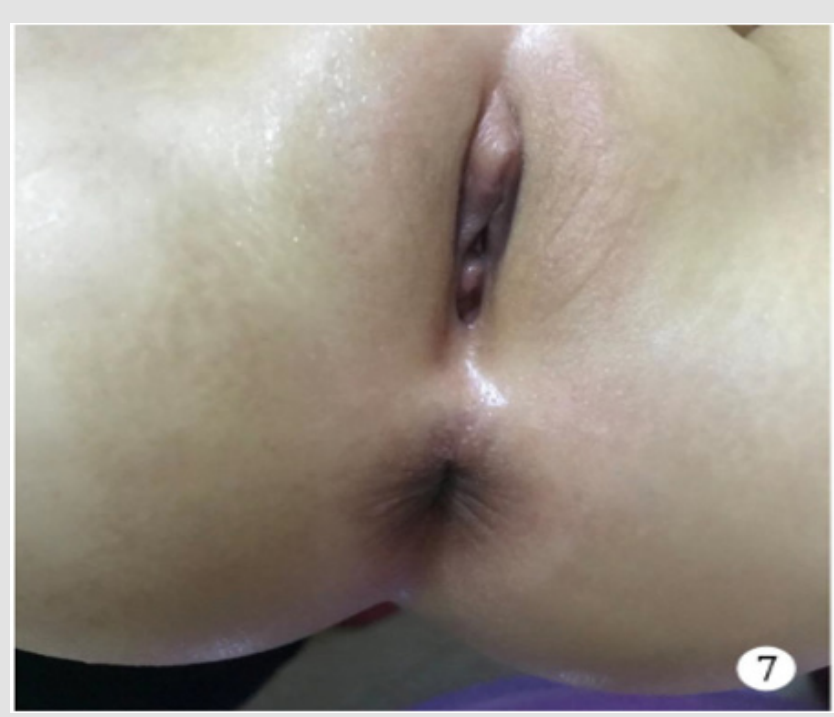

Figure 7: No new warts were found during follow-up for 1 year.

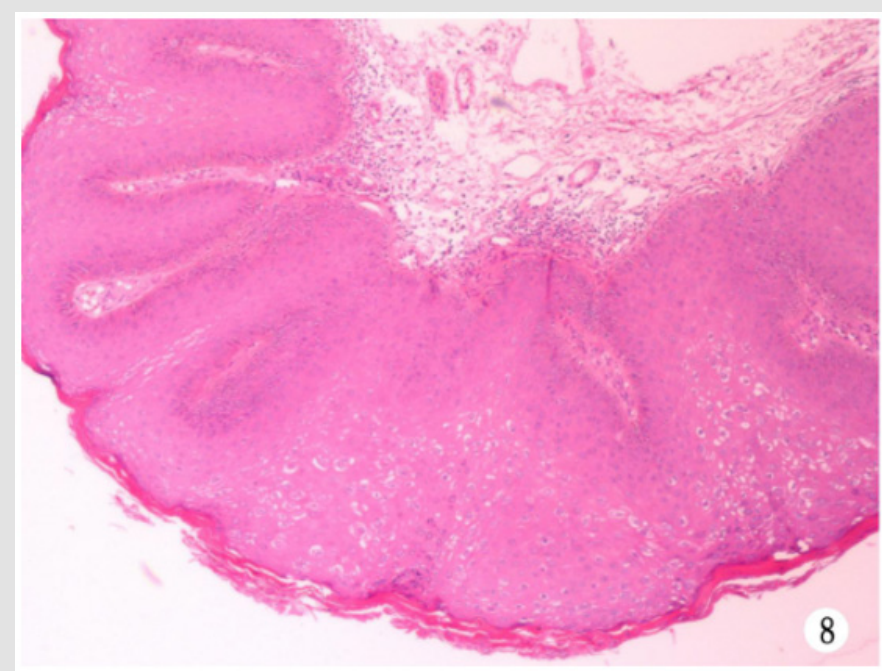

Figure 8: The histopathology of the skin lesions showed hyperkeratosis of epidermis with parakeratosis, acanthosis, papillomatosis and vacuolated cells in the upper part of stratum spinosum.

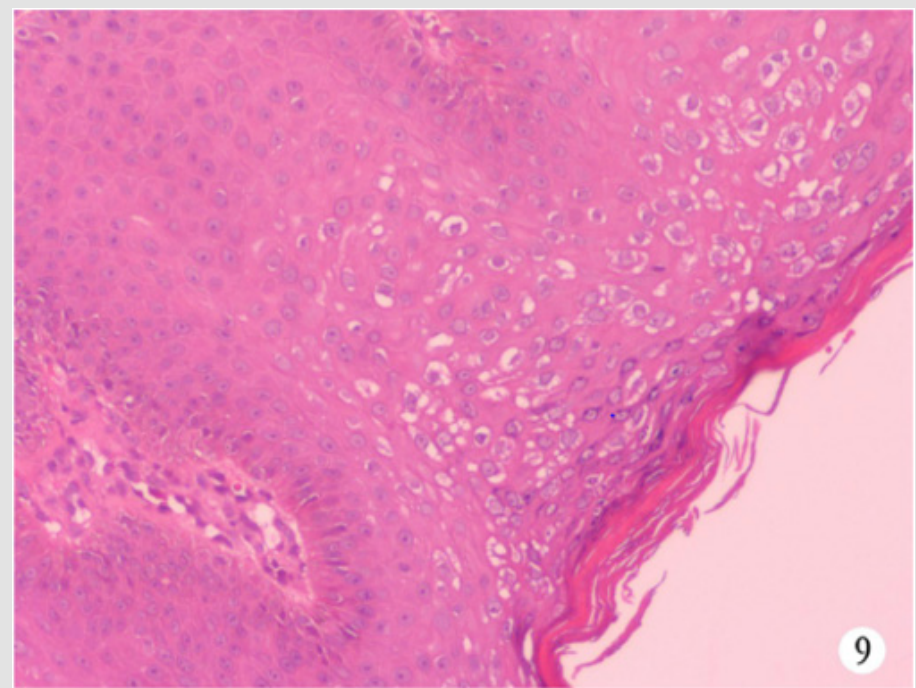

Figure 9. 
Initially, treatment was started with regular disinfection of local skin, wet application of 20\%ALA solution on skin lesions, phototherapy after wrapping with plastic wrap for 3 hours, irradiation of skin lesions with 635nmLED light source with energy density of $100 \sim 120 \mathrm{~J} / \mathrm{cm}^{2}$ and irradiation time of $20 \sim 30 \mathrm{~min}$. The interval between the two treatments was $7 \sim 10$ days.After four consecutive treatments, the warts did not disappear, and the re-examination of HPV51 was still positive. Therefore, the patient was treated with chinese drug paiteling for three-stage therapy [4]. In the first stage, the wart body and its surrounding area were wet application with gauze soaked in original solution for $15 \mathrm{~min}$ each time, and stopping the drug after 3 consecutive days for 4 days was a course of treatment. In the second stage, after the warts body fell off and the wound healed (Figures $3 \& 4$ ), another $2 \sim 3$ courses of treatment were repeated to further remove the subclinical virus. In the third stage, wet application with 4-6 layers of gauze soaked in 1:50 diluent of petaline $(1 \mathrm{ml}$ of stock solution plus $50 \mathrm{ml}$ of distilled water) on the original damage parts to prevent recurrence (Figures 5 \& 6), each time for about $10 \mathrm{~min}$. Once a day in the first month and once every two days in the second and third months. No new warts were found during follow-up for 1 year (Figure 7), and the re-examination was negative for HPV51.

\section{Discussion}

CA is a proliferative lesion of anogenital region caused by HPV infection, which is mostly found in young people aged 18-35 years old [5]. However, in recent years,with the increasing number of adults, the incidence of CA in children has been increasing year by year, and it is more common in girl patients [6]. The route of transmission, HPV genotype, treatment, outcome and prognosis are different from those of adults. Perianal region is the most common site of CA lesions in children. Its transmission routes are various, mainly non-sexual transmission, among which indirect infection in close contact with affected parents is more common [7]. Here reported case was no condyloma acuminatum in the child's family. Before the onset of the disease, the child used to play in a public swimming pool. The child has a high possibility of indirect infection due to contact with the swimming pool contaminated by CA patients. The most common genotypes of HPV in children were HPV6 and HPV11. HPV genotyping in some children is unclear and the test results are negative [8]. The HPV genotype of the child in this case is high-risk HPV51, which is rarely reported at present. At present, there are many different methods for the treatment of childhood CA, with the goal of completely removing wart and reducing the recurrence.

The treatment methods mainly include physical photoelectricity, surgical resection and topical application. However, the recurrence rate of childhood CA is still high, so comprehensive consideration is needed to ensure the safety, effectiveness and tolerability of the treatment. The treatment methods mainly include physical photoelectricity, surgical resection and topical application. However, the recurrence rate of childhood CA is still high, so comprehensive consideration is needed to ensure the safety, effectiveness and tolerability of the treatment. Previous research showed that 5-aminolevulinic acid photodynamic therapy (ALA-PDT) was effective in the treatment of condyloma acuminatum in children, and the recurrence rate was low, which indicates that ALA-PDT is a safe and easily tolerated effective method for the treatment of CA in children and the prevention of recurrence [9]. In this case, the warts did not disappear after 4 times of consecutive treatment with ALA-PDT, and the curative effect was poor, which may be related to the infection of high-risk HPV51 genotype.

Huang Gengshi [10] found that condyloma acuminatum patients with high-risk HPV genotype infection are more likely to develop persistent infection with a longer course of disease. In addition, the children's immune system is not perfect, which is difficult to effectively remove HPV virus, so the efficacy of ALA-PDT therapy is poor. Paiteling is a pure Chinese medicine preparation for external use developed and produced by Beijing Paite Biotechnology Limited Company, China. Its main components are Hedyotis Diffusa, Folium Isatidis, Radix Sophorae Flavescentis, Fructus Bruceae, Fructus Cnidii, etc.It is effective in the treatment of high-risk HPV infection and has a high cure rate for recurrent condyloma acuminatum [11]. Its pharmacological mechanism is mainly to inhibit the proliferation of tumor cells through cytotoxicity, and promote the exfoliation of epidermal cells of warts and surrounding latent viruses by accelerating the metabolism of epidermal cells [12]. Children have large fear, low tolerance to pain and poor compliance, so they are often unable to cooperate with treatment. Compared with local treatment methods such as cryotherapy, laser and electrocautery, external use of paiteling for children with CA has the advantages of high cure rate, easy tolerance and low side effects [4], especially for children with high-risk HPV infection.The application of paiteling may provide a new therapeutic method for clinical treatment of refractory condyloma acuminatum in children.

\section{Conflict of Interest}

The authors have no proprietary interest in any aspect of the study.

\section{References}

1. IU P, CI, EF D (2015) Human Papillomavirus and Genital Warts: A Review of the Evidence for the 2015 Centers for Disease Control and Prevention Sexually Transmitted Diseases Treatment Guidelines. Clinical infectious diseases: an official publication of the Infectious Diseases Society of America pp. S849-855.

2. Chamseddin BH, Agim NG, Jarin J, Wilson EE, Mir A (2019) Therapy for anogenital verrucae in preadolescent children with topical and systemic treatment. Pediatr Dermatol 36(5): 623-627.

3. Ping Ping Tao, Weiping Zheng, Xiaohua Meng (2017) Effect of paiteling on human papillomavirus infection of the cervix. MOLECULAR AND CLINICAL ONCOLOGY 7(6): 957-964.

4. Qiguo Z, Mian W, Yijin H (2017) The Efficacy and Safety of Paitelin in the Treatment of Condyloma Acuminatum. China Health Standard Management 8(24): 114-116. 
5. Fanghui Z, Li Z (2019) Prophylactic human papilloma virus vaccines launch the era of comprehensive cervical cancer control. Chinese Journal of Preventive Medicine 53(1): 10-12.

6. Bouscarat F, Pelletier F, Fouere S, Janier M, Bertolloti A, Aubin F, et al. (2016) External genital warts (condylomata). Annales De Dermatologie Et De Venereologie 143(11): 741-745.

7. S Bussen, Marc Suetterlin, U Schmidt, D Bussen (2012) Anogenital Warts in Childhood - Always a Marker for Sexual Abuse? Geburtshilfe Frauenheilkd 72(1): 43-48.

8. Egawa N, Doorbar J (2017) The low-risk papillomaviruses. Virus Research 231: 119-127.

9. Ying Z, Li X, Dang H (2013) 5-aminolevulinic acid-based photodynamic therapy for the treatment of condylomata acuminata in Chinese patients: a mete-analysis. Photoimmunology \& Photomedicine 29(3): 149-159.

ISSN : 2574-1241

DOI: 10.26717/BJSTR.2020.26.004412

Yang Meng. Biomed J Sci \& Tech Res

(C) This work is licensed under Creative

Submission Link: https://biomedres.us/submit-manuscript.php
10. Geng-shi H, Guang-ren L, Yong-zhi H, Jing L (2017) The Influence of HRHPV Genotypes on Persistent Patients With Condyloma Acuminatum. The Chinese Journal of Dermatovenereology 31(10): 1100-1101+1104.

11. Yan W, Liqing H, Xuzi C, Xuefeng W (2019) Efficacy and Safety of Paiteling in Treating Patients with Persistent High-risk HPV Chinese General Practice 22(11): 1323-1327.

12. Jing Z, Rongying H, Qianying Z (2017) Clinical observation of clinical efficacy of treatment to different subtypes of HPV infected condyloma acuminata by Paiteling and microwave combined with recombinant human interferon $\alpha$-2b cream. CHINESE Journal of AIDS \& STD 23(11): 1054-1056+1067

$\begin{array}{ll}\text { BIOMEDICAL } & \text { Assets of Publishing with us } \\ \text { RESEARCHES } & \text { - Global archiving of articles } \\ \text { - Immediate, unrestricted online access } \\ \end{array}$

